\title{
Coverage of human papillomavirus vaccination during the first year of its introduction in Spain
}

A Limia (alimia@mspsi.es)'1, I Pachón ${ }^{1}$

1. Directorate General of Public Health, Ministry of Health, Social Policy and Equity, Madrid, Spain

Citation style for this article:

Limia A, Pachón I. Coverage of human papillomavirus vaccination during the first year of its introduction in Spain.

Euro Surveill. 2011;16(21):pii=19873. Available online: http://www.eurosurveillance.org/ViewArticle.aspx?Articleld=19873

Article published on 26 May 2011

The decision to introduce human papillomavirus (HPV) vaccination into the national immunisation programme in Spain was made in October 2007, recommending vaccination of girls aged between 11 and 14 years with three doses of HPV vaccine. All 19 regions of the country (17 Autonomous Communities and two Autonomous Cities) introduced HPV vaccination gradually into their immunisation programmes between November 2007 and the last school term of 2008. Eight regions administered the vaccine in healthcare centres and 11 in schools. In the first year of the introduction of HPV vaccination, coverage of the first and third doses was assessed, to determine the proportion of girls who did not complete the vaccination. On the basis of the available data, the Ministry of Health estimated that coverage for the first dose was $87.2 \%$ (range: $73.9-98.9 \%$; $95 \% \mathrm{Cl}: 71.8$ to 100 ) and $77.3 \%$ (range: $62.2-97.4 \%$; $95 \% \mathrm{Cl}: 57.9$ to 96.7 ) for the third dose. Higher uptake was observed when the vaccination was carried out in schools compared with healthcare centres, but the difference was not statistically significant. Negative messages in the media during implementation of the HPV vaccination programme may have had some influence on the attitudes of adolescent girls and/or their parents towards HPV vaccination and may be partly responsible for the observed vaccination dropout rate.

\section{Background}

Human papillomavirus (HPV) causes one of the commonest sexually transmitted infections and is also the main cause of cervical cancer in the world. About $70 \%$ of cervical cancer cases are associated with chronic infection with HPV types 16 and 18 [1]. HPV types 6 and 11 cause a high percentage of low-risk cervical dysplasia and more than $90 \%$ of genital warts. HPV infection is associated with age and early sexual debut [2].

In Spain there is no national cancer registry, therefore no direct information about the number of cervical cancer cases per year is available for the country as a whole. The International Agency for Research on Cancer uses local incidence data and national mortality data to estimate incidence and mortality due to cervical cancer in Spain. For 2008, a total of 1,948 new cases (agestandardised incidence rate of 6.3 cases per 100,000 population) and 712 deaths (age-standardised mortality rate of 1.9 per 100,000 population) were estimated for Spain [3]. In 2008, both HPV-specific incidence and mortality were among the lowest in southern Europe [4].

The European Commission granted a marketing authorization for two HPV vaccines in the European Union: the tetravalent Gardasil in October 2006 (which contains HPV types 16, 18, 6 and 11) and the bivalent Cervarix in September 2007 (containing HPV types 16 and 18) [5,6]. A three-dose vaccination course is recommended, at 0 , 2 and 6 months for Gardasil [7] and 0, 1 and 6 months for Cervarix [8].

The main goal of the vaccination is to prevent infection by the HPV types included in the vaccine and to decrease acute and chronic disease burdens caused by the infection, particularly precancerous lesions and cancer.

\section{Decision-making process for the introduction of a new vaccine into the National Immunisation Programme in Spain}

Spain has a national health system with universal access funded from general taxation [9]. It is largely decentralised and the country's 19 regions (17 Autonomous Communities and two Autonomous Cities) are responsible for the management and delivery of vaccination programmes. The Interterritorial Council, coordinated by the Ministry of Health, is the decision-making body responsible for the coordination of all programmes within the national health system in order to ensure cohesion and equity. Resolutions are approved by consensus and materialise through recommendations.

The Commission on Public Health, also coordinated by the Ministry of Health, proposes public health programmes or makes recommendations on public health issues to the Interterritorial Council. The Vaccination Programmes and Registration Board (Vaccines Board) is the technical group of the Commission on Public Health that provides recommendations relating to 
immunisation based on epidemiological, scientific and public health information. Approved recommendations are then incorporated into the National Immunisation Programme. Regions may also offer vaccines that are not in the national programme.

In February 2007 the Vaccines Board recommended the introduction of HPV vaccination. This recommendation was approved by the Commission on Public Health in September and by the Interterritorial Council in October that year [10]. The Council decided to include HPV vaccination within the framework of the country's cervical cancer prevention strategy. It recommended that the vaccine be introduced before the end of 2010, for girls between the ages of 11 and 14 years, in accordance with requirements, priorities and logistics of regional vaccination programmes and the availability and supply of vaccines in each region. In November 2007, the Commission on Public Health agreed that girls aged 14 years were the best cohort to vaccinate. No specific target coverage was set as an objective of the programme.

\section{Implementation of HPV vaccination in Spain}

After the consensus reached by the Interterritorial Council in October 2007, regions began to implement HPV vaccination gradually into their immunisation programmes, starting in November 2007. Three regions began the vaccination during the school winter term of 2007/08, six regions carried out the vaccination in the first term of 2008 and 10 in the last term of 2008 .

The purchase and distribution of the vaccine were carried out independently by each region: 13 chose Gardasil and the other six chose Cervarix . Each region also covered all expenses related to the administration of vaccines in their territory and supported the introduction of the programme with publicity campaigns and communication strategies independently.

Most regions $(n=13)$ chose to vaccinate girls aged 14 years, in line with the Commission on Public Health's decision. Three regions vaccinated girls aged 13 years, one vaccinated girls in their last year of primary education (aged 11-12 years) and two vaccinated girls in the first year of secondary education (aged 13-14 years). Two regions have temporarily extended the vaccination age in their territory: both have implemented the programme in schools and included young women attending three school years ahead of those included in the programme.

Eight regions administered the vaccine in healthcare centres and 11 in schools.

\section{Estimation of HPV vaccination coverage}

Monitoring of HPV vaccination coverage is carried out as part of the regular monitoring of coverage of administered vaccines included in the National Immunisation Programme. Predefined indicators are estimated annually at regional level and are sent to the Ministry of
Health on a voluntary basis. The information is publicly available on the Ministry of Health web site [11].

Vaccination uptake is estimated by nominal registry in four regions and by an indirect method - using the total number of administered doses (reported by health care professionals) in the targeted female population - in the other regions. To estimate HPV vaccine coverage, the uptake of the three doses was assessed, but for the first year after the introduction of HPV vaccination, uptake of the first and third doses was included, to assess the dropout rate. Coverage was calculated as the proportion of the targeted population that received the first and the third doses of any HPV vaccine.

In the first year of HPV vaccine implementation (academic year 2008 to 2009), 14 regions sent information to the Ministry of Health about first-dose uptake and 18 regions about third-dose uptake in their territory (one region did not send any information on HPV vaccine uptake). The data indicated that coverage with one dose was $87.2 \%$ (range: $73.9-98.9 \%$; $95 \% \mathrm{Cl}: 71.8$ to 100 ) in the 14 regions that sent the information. Coverage decreased when looking at the proportion of girls receiving the three doses: in the 18 regions that sent the information, the coverage was $77.3 \%$ (range: 62.2-97.4\%, 95\% Cl: 57.9 to 96.7). Only one region had a third-dose coverage lower than $70 \%$, in six regions it was $70-80 \%$, in five it was $80-90 \%$ and in six, over $90 \%$ coverage was achieved [11].

The observed difference between one- and three-dose uptake in regions reporting both sets of data was 9.9 percentage points, with high variability among the regions, ranging between 0.5 and 16.4 percentage points.

Regarding the venue of administration of the vaccines, coverage was $84.2 \%$ (range: $73.7-97.4 \%$, 95\% Cl: 62.7 to 100 ) in regions that implemented the programme in schools and $70.1 \%$ (range: $62.2-85.7 \%, 95 \% \mathrm{Cl}: 36.2$ to 100$)$ for those that vaccinated in healthcare centres; however, the observed difference is not statistically significant.

\section{Discussion and conclusion}

During the first year of the HPV vaccination programme in Spain, vaccination with three doses was $77.3 \%$ for the targeted adolescent girls. Other countries of the European Union (EU) showed variable vaccination coverage of three doses of HPV vaccine in the respective targeted age groups during the first year: $44 \%$ in Belgium [12], $53.1 \%$ in Italy [13], and $80.9 \%$ in the United Kingdom [14]. In 2009, coverage of other vaccines administered in adolescents in Spain was $74.1 \%$ (for the vaccine against tetanus and diphtheria, administered at age $14-16$ years) and $82.7 \%$ (for hepatitis B vaccine, administered at age 10-14 years) [11].

A dropout of 9.9 percentage points, between first-dose uptake $(87.2 \%)$ and third-dose uptake (77.3\%), has 
been observed, but possible reasons for this have not been analysed. For hepatitis $B$ vaccine, which is also administered in three doses, only information about coverage with three doses is gathered at central level so we do not know what the dropout rate is. Similar dropout figures between first- and third-dose uptake of HPV vaccines have been observed in the United Kingdom [14] and Italy [13], of 7.7 and 13.2 percentage points, respectively; nevertheless, efforts should be made to completely vaccinate girls that start the vaccination.

Although the anti-vaccination movement has had neither an important influence on vaccination uptake nor important coverage in the media in Spain, the introduction of HPV vaccination into the National Immunisation Programme created some controversy among the public and healthcare workers, which was covered by the media. Some healthcare workers claimed that the available information regarding efficacy and safety of the HPV vaccines had some important gaps and because of that, together with the high price of the vaccines, they questioned the benefit of introducing HPV vaccination [15].

During this time of public and professional uncertainty about HPV vaccination, two cases of status epilepticus with myoclonus were reported in two girls after administration of the second dose of Gardasil in schools in the same city, in February 2009 [16]. A resulting pharmacovigilance signal was notified to the European Medicines Agency and issues related to the cases were extensively covered by all media at regional and national level. This intense media attention lasted for two and a half months, until it was determined that the adverse events were not related to the vaccine (following investigation by the Spanish and European medicines agencies of the adverse events and the quality of the specific vaccine batch) $[16,17]$. The negative effect of the media coverage has not been analysed in detail but it is thought likely that it had some influence on the attitude of adolescent girls and/or their parents towards vaccination. This might have had been partly responsible for the observed dropout rate. In contrast, in the United Kingdom, where a similar dropout rate for HPV vaccination was found, positive media coverage surrounding the introduction of the vaccination programme has been considered as influencing public perceptions about acceptability of the vaccination and contributing to the good level of vaccination coverage [18]. Special attention should be paid to tailoring communication strategies in Spain to increase positive perceptions of HPV vaccination in adolescent girls and parents.

The observed difference of coverage according to the venue of HPV vaccination in Spain was not statistically significant. In the first year after HPV vaccine was introduced in England, a high level of vaccine uptake $(80.1 \%)$ was achieved in eligible girls in the routine cohort (aged 11-13 years), who were mostly (94.2\%) vaccinated through a school-based programme. Delivery through general practitioners resulted in lower uptake rates compared with those related to delivery through schools for each dose, and this was particularly noticeable for third-dose uptake [14]. The coverage for the routine cohort was higher than that seen in the 17-18-year-old catch-up cohort (31.8\%), who were vaccinated in various venues $(31.4 \%$ were vaccinated in schools, $60 \%$ in general practitioners' practices and $8.6 \%$ in community clinics). It was not stated whether the coverage differences seen according to venue of vaccine administration were statistically significant in this study in England [14]. Further data regarding regional strategies should be analysed in Spain to better understand the possible influence on coverage of the venue of implementation of immunisation programmes targeting adolescents.

As with other vaccines in the National Immunisation Programme, a high uptake is needed to maximise the results. The long-term impact of HPV vaccination is difficult to predict and the duration of immunity conferred by the vaccines is not known. A recent study modelling the impact of HPV vaccination in the United Kingdom has suggested that vaccinating a cohort of young women at $80 \%$ coverage will result in a $38-82 \%$ reduction in cervical cancer incidence and $44-100 \%$ reduction in anogenital warts incidence after 60 years of an ongoing vaccination programme if vaccine protection lasts 20 years on average [19]. In addition, it should be borne in mind that the HPV vaccination does not eliminate the need for cervical cancer screening, even for women vaccinated against HPV types 16 and 18, who will still be at risk from other high-risk types [20]

Parents' attitudes may also play a role in the uptake of HPV vaccination by adolescents, given that the vaccine prevents a sexually transmitted infection. The effect of social inequalities on the uptake of HPV vaccination has been shown in a prospective cohort study in Manchester, United Kingdom, which observed that parents who did not consent to their daughter's vaccination at school were from more deprived and ethnic minority backgrounds [21,22].

There are a couple of limitations in our analysis. First, overall national three-dose coverage was calculated without the information from one region, representing less than $5 \%$ of the Spanish population. It should be pointed out that coverage for other vaccines notified in previous years from this region did not fall into any of the coverage extremes, so the same may be true for HPV vaccination. Second, other information about the campaigns conducted at regional level, such as communication, media coverage and other recruitment strategies, has not been analysed and may also play a role in coverage besides the venue of administration.

In conclusion, in the first year of implementation of HPV vaccination in Spain, coverage was similar to that for other vaccines given to adolescents in the country. 


\section{Our findings demonstrate that the programme should be strengthened to reduce the dropout rate.}

\section{Acknowledgments}

The authors wish to acknowledge the members of the Vaccines Board in Spain for the implementation of the HPV programme in the Autonomous Communities and Autonomous Cities and their contribution of their programme information to the Ministry of Health, Social Policy and Equity.

\section{References}

1. Schiffman M, Castle PE, Jeronimo J, Rodriguez AC, Wacholder S. Human papillomavirus and cervical cancer. Lancet. 2007; 370(9590):890-907.

2. Poolman EM, Elbasha EH, Galvani AP. Vaccination and the evolutionary ecology of human papillomavirus. Vaccine. 2008;26 Suppl 3:C25-30.

3. International Agency for Research on Cancer (IARC). GLOBOCAN 2008. Fast stats. Spain. Lyon: IARC. [Accessed 27 Apr 2011]. Available from: http://globocan.iarc.fr/factsheets/ populations/factsheet.asp?uno $=724$

4. World Health Organization (WHO)/ Institut Català d'Oncologia (ICO) Information Centre on HPV and Cervical Cancer (HPV Information Centre). Human papillomavirus and related cancers in Spain. Summary report 2010. [Accessed 17 May 2011]. Available from: http://apps.who.int/hpvcentre/statistics/ dynamic/ico/country_pdf/ESP.pdf?CFID $=4005139 \&$ CFTOK $\mathrm{EN}=50211239$

5. European Medicines Agency (EMA). Gardasil. London: EMA. [Accessed 27 Apr 2011]. Available from: http://www.ema. europa.eu/ema/index.jsp?curl=pages/medicines/human/ medicines/000703/human_med_000805.jsp\&murl=menus/ medicines/medicines.jsp\&jsenabled=true

6. European Medicines Agency (EMA). Cervarix. London: EMA. [Accessed 9 May 2011]. Available from: http://www.ema. europa.eu/ema/index.jsp?curl=pages/medicines/human/ medicines/000721/human_med_000694.jsp\&murl=menus/ medicines/medicines.jsp

7. European Medicines Agency (EMA). Annex I. Summary of product characteristics. [Gardasil]. Updated 14 Sep 2010. Available from: http://www.ema.europa.eu/docs/ en_GB/document_library/EPAR_-_Product_Information/ human/000703/WC500021142.pdf

8. European Medicines Agency (EMA). Annex I. Summary of product characteristics. [Cervarix]. Updated 10 Mar 2011. Available from: http://www.ema.europa.eu/docs/ en_GB/document_library/EPAR_-_Product_Information/ human/000721/WC500024632. pdf

9. National Health System, Spain 2010. Madrid: Ministry of Health and Social Policy, Health Information Institute; 2010. Available from: http://www.msps.es/organizacion/sns/docs/sns2010/ Main.pdf

10. Ministry of Health and Social Policy. Virus del papiloma humano. Situación actual, vacunas y perspectivas de su utilización. [Human papilomavirus. Current situation, vaccines and prospect of their use]. Feb 2007. Spanish. Available from: http://www.msps.es/profesionales/saludPublica/ prevPromocion/vacunaciones/docs/VPH_2007.pdf

11. Ministry of Health, Social Policy and Equity. Coberturas de vacunación. Datos estadísticos. [Vaccination coverage. Statistical data]. [Accessed 10 Oct 2010]. Spanish. Available from: http://www.msps.es/profesionales/saludPublica/ prevPromocion/vacunaciones/coberturas.htm

12. Simoens C, Sabbe M, Van Damme P, Beutels P, Arbyn M. Introduction of human papillomavirus (HPV) vaccination in Belgium, 2007-2008. Euro Surveill. 2009:14(46):pii=19407. Available from: http://www.eurosurveillance.org/ViewArticle. aspx?Articleld $=19407$

13. Giambi C. Ricognizione delle decisioni regionali in merito alla vaccinazione anti-HPV e primi dati di copertura vaccinale a fine anno 2009. [Survey of regional decisions on HPV vaccination and the first data of vaccination coverage at year-end 2009]. [Accessed 9 May 2011]. Italian. Available from: http://www. epicentro.iss.it/focus/hpv/pdf/HPV-2009.pdf
14. Sheridan A, White JL, Barlow T, Soldan K. Annual HPV vaccine uptake in England: 2008/09. 6 Jan 2010. London: Health Protection Agency, Department of Health. Available from: http://www.dh.gov.uk/prod_consum_dh/groups/ dh_digitalassets/@dh/@en/@ps/documents/digitalasset/ dh 111676.pdf

15. Martin-Llaguno M, Alvarez-Dardet C. [Withdrawal of an advertising campaign to promote the quadrivalent human papilloma virus vaccine in Spain]. Gac Sanit. 2010;24(1):75-7. Spanish.

16. European Medicines Agency (EMA). European Medicines Agency recommends continued vaccination with Gardasil. Press release. EMEA/CHMP/103339/2009. 19 Feb 2009. Available from: http://www.ema.europa.eu/docs/en_GB/ document_library/Press_release/2009/11/WC500011828.pdf

17. Spanish Medicines Agency, Ministry of Health and Social Policy. Seguridad de las vacunas frente al virus del papiloma humano: conclusiones del comité de expertos. [Human papilomavirus vaccines safety: expert committee conclusions]. 23 Apr 2009. Spanish. Available from: http://www.aemps. es/en/actividad/alertas/usoHumano/seguridad/docs/2009/ NI_2009-06_segVacuPapilomaHumano.pdf

18. Hilton S, Hunt K, Langan M, Bedford H, Petticrew M. Newsprint media representations of the introduction of the HPV vaccination programme for cervical cancer prevention in the UK (2005-2008). Soc Sci Med 2010;70(6):942-50.

19. Choi YH, Jit M, Gay N, Cox A, Garnett GP, Edmunds WJ. Transmission dynamic modelling of the impact of human papillomavirus vaccination in the United Kingdom. Vaccine. 2010;28(24):4091-102.

20. European Centre for Disease Prevention and Control (ECDC). Guidance for the introduction of HPV vaccines in EU countries. Stockholm: ECDC; 2008. Available from: http://www. ecdc.europa.eu/en/publications/Publications/0801_GUI_ Introduction_of_HPV_Vaccines_in_EU.pdf

21. Brabin L, Roberts SA, Stretch R, Baxter D, Chambers G, Kitchener $\mathrm{H}$, et al. Uptake of first two doses of human papillomavirus vaccine by adolescent schoolgirls in Manchester: prospective cohort study. BMJ. 2008;336(7652):1056-8.

22. Roberts SA, Brabin L, Stretch R, Baxter D, Elton P, Kitchener H, et al. Human papillomavirus vaccination and social inequality: results from a prospective cohort study. Epidemiol Infect. 2011;139(3):400-5. 